\title{
Longterm follow up of transjugular intrahepatic portosystemic stent shunt (TIPSS) for the treatment of portal hypertension: results in 130 patients
}

\author{
A J Stanley, R Jalan, E H Forrest, D N Redhead, P C Hayes
}

\begin{abstract}
Background-Transjugular intrahepatic portosystemic stent shunts (TIPSS) are increasingly being used to manage the complications of portal hypertension. This study reports on the follow up on 130 patients who have undergone TIPSS.

Patients and Methods-One hundred and thirty patients (81 male), mean (SD) age $54 \cdot 7(12 \cdot 5)$ years underwent TIPSS. The majority $(64 \cdot 6 \%)$ had alcoholic cirrhosis and $53 \cdot 2 \%$ had Childs C disease. Indications were: variceal haemorrhage $(76 \cdot 2 \%)$, refractory ascites $(13 \cdot 1 \%)$, portal hypertensive gastropathy $(4 \cdot 6 \%)$, others $(6 \cdot 1 \%)$. Shunt function was assessed by Doppler ultrasonography and two then six monthly portography and mean follow up for survivors was 18.0 months (range 2-43.5).

Results-The procedure was successful in $119(91 \cdot 5 \%)$. Sixty three episodes of shunt dysfunction were observed in $45(37.8 \%)$ patients. Variceal rebleeding occurred in $16(13.4 \%)$ patients and was always associated with shunt dysfunction. Twenty $(16 \cdot 8 \%)$ patients had new or worse spontaneous encephalopathy after TIPSS and $11(64 \cdot 7 \%)$ patients had an improvement in resistant ascites. Thirty day mortality was $21 \cdot 8 \%$ and one year survival $62 \cdot 5 \%$.

Conclusion-TIPSS is an effective treatment for variceal bleeding, resistant ascites, and portal hypertensive gastropathy. Rebleeding is invariably associated with shunt dysfunction, the frequency of which increases with time, therefore regular and longterm shunt surveillance is required.
\end{abstract}

(Gut 1996; 39: 479-485)

Medicine

A J Stanley

$R$ Jalan

E H Forrest

P C Hayes

and Radiology

D N Redhead

Royal Infirmary of Edinburgh, Edinburgh Correspondence to: Dr A J Stanley, Department of Medicine, Royal Infirmary of Edinburgh, EH3 9YW.

Accepted for publication 27 February 1996

Keywords: transjugular intrahepatic portosystemic stent shunt, portal hypertension, varices, ascites.

Since their introduction into clinical practice in $1989,{ }^{1}$ transjugular intrahepatic portosystemic stent shunts (TIPSS) are being increasingly used in the management of both variceal haemorrhage and refractory ascites.

Variceal haemorrhage is the most dramatic complication of portal hypertension, occurring in $30 \%$ patients with cirrhosis during their lifetime. ${ }^{2}$ Mortality from the first bleed approaches $50 \%{ }^{3}$ and $70-100 \%$ patients have recurrent bleeding. Immediate control of bleeding can be achieved in $90 \%$ of patients by balloon tamponade, ${ }^{4}$ vasoactive drug therapy, ${ }^{5}$ sclerotherapy, ${ }^{6}$ variceal band ligation ${ }^{7}$ or surgery, ${ }^{89}$ with the greatest reduction in rebleeding rates achieved by surgical shunts. ${ }^{10}$ The main limitations of shunt surgery are its high perioperative mortality and frequency of debilitating postoperative encephalopathy, which approaches $30 \%$ in some series. ${ }^{11}$ TIPSS has been shown to control active variceal haemorrhage and reduce rebleeding rates while having lower procedure related complications and probably less post-treatment encephalopathy ${ }^{12}$ compared with surgical shunts. Follow up of patients with TIPSS is however limited, which is important as encephalopathy following surgical shunts commonly was delayed and shunt patency after TIPSS may decrease with time.

Refractory ascites is associated with advanced liver disease and a poor prognosis. ${ }^{13}$ The current therapeutic options of repeated paracentesis and a peritoneovenous shunt are far from ideal and associated with significant morbidity and prolonged hospital stay and do not affect survival. ${ }^{14}$ TIPSS permits better control of ascites and improves renal sodium excretion $^{15}$ although the mortality seems unchanged in the limited reported data. TIPSS has also been used and found to be effective in the control of other conditions such as portal hypertensive gastropathy, splenomegaly, ${ }^{16}$ Budd-Chiari syndrome, ${ }^{17}$ and hepatic hydrothorax. ${ }^{18}$ The present available literature is limited both by short duration of follow up and small patient numbers. Up until August 1995, we had carried out 130 TIPSS procedures in our unit and the aim of this paper is to present our results and more importantly the longterm follow up.

\section{Methods}

\section{PATIENTS}

From 1991 to 1995, TIPSS insertion was attempted in 130 patients, with successful placement of the stent in 119 cases $(91.5 \%)$. Table I shows the details of the patients. Eighty one patients were male with mean (SD) age of $54.7(12.5)$ years (range 9 to 83 years). Over the same period, a total of 220 patients were treated for variceal haemorrhage at our institution. 
TABLE I Patient characteristics $(n=130)$ before TIPSS

\begin{tabular}{lc}
\hline Sex $(M / F)$ & $81 / 49$ \\
\hline Age (y) & \\
mean (SD) & $54 \cdot 7(12 \cdot 5)$ \\
range & $9-83$ \\
Aetiology of liver disease (\%) & $84(64 \cdot 6)$ \\
alcoholic cirrhosis & $12(9 \cdot 2)$ \\
cryptogenic cirrhosis & $11(8 \cdot 5)$ \\
primary biliary cirrhosis & $5(3 \cdot 8)$ \\
hepatitis C & $5(3 \cdot 8)$ \\
hepatitis B & $3(2 \cdot 3)$ \\
cystic fibrosis & $2(1 \cdot 5)$ \\
primary sclerosing cholangitis & $2(1 \cdot 5)$ \\
autoimmune hepatitis & $6(4 \cdot 6)$ \\
other & $9 \cdot 9(2 \cdot 7)$ \\
Childs-Pugh score (mean (SD)) & $10(7 \cdot 9)$ \\
Childs-Pugh grade (\%) & $49(38 \cdot 9)$ \\
A & $67(53 \cdot 2)$ \\
B & $73(56 \cdot 2)$ \\
C & $26(20 \cdot 0)$ \\
Indication (\%) & $17(13 \cdot 1)$ \\
oesophageal varices & $6(4 \cdot 6)$ \\
gastric varices & $5(3 \cdot 8)$ \\
refractory ascites & $3(2 \cdot 3)$ \\
portal hypertensive gastropathy & $35(26 \cdot 9)$ \\
ectopic varices & $19(14 \cdot 6)$ \\
other & $10(7 \cdot 7)$ \\
Emergency procedure (\%) & $86(66 \cdot 2)$ \\
Clinical features (\%) & $44(33 \cdot 8)$ \\
artificially ventilated & \\
haemodynamic compromise & \\
ascites & \\
hepatic encephalopathy & \\
\hline
\end{tabular}

The aetiology of portal hypertension was alcoholic cirrhosis (ALD) in $84(64 \cdot 6 \%)$ patients, with other aetiologies shown in Table I. One patient had $\alpha_{1}$ antitrypsin deficiency and one Budd-Chiari syndrome. Four patients were non-cirrhotic (one each with amyloid, idiopathic portal hypertension, polycystic disease, and nodular regenerative hyperplasia). Most cirrhotic patients (53.2\%) had Childs-Pugh grade $\mathrm{C}$ disease at time of TIPSS with a mean (SD) overall Childs-Pugh score of $9.9(2 \cdot 7)$.

The indication for TIPSS was oesophageal variceal bleeding in $73(56.2 \%)$ patients who had either continued bleeding despite two sessions of sclerotherapy or were part of a trial comparing band ligation with TIPSS in the prevention of rebleeding (see Table I). The indication was ectopic varices in five $(3.8 \%)$ patients (two rectal, two stomal, and one duodenal) and painful splenomegaly, hypersplenism and embolisation of a spontaneous shunt in one patient each. Thirty five procedures $(26.9 \%)$ were carried out as an emergency with $19(14.6 \%)$ patients receiving assisted ventilation and $23(17 \cdot 7 \%)$ patients treated with balloon tamponade prior to TIPSS.

\section{STUDY DESIGN}

The technique of TIPSS placement was based on the original method described by Richter ${ }^{19}$ and is described in detail elsewhere. ${ }^{20}$ Routine pre-procedural mesenteric angiography was undertaken in the first 32 patients to guide portal vein puncture and in 27 subsequent patients, Doppler ultrasonography was used to identify the site of portal vein bifurcation. In the last 71 patients however, no routine imaging was undertaken to localise the portal vein pre-TIPSS, although ultrasonography was used prior to the procedure to exclude portal vein thrombosis. These changes have evolved as a result of ongoing audit at our unit.
Once successful puncture of the portal vein was achieved, 2-3 Palmaz stents (Johnson and Johnson) (20 patients), or 1-2 Wallstents (Schneider US Stent Division) (99 patients) were inserted to reduce the portal pressure gradient (defined as: (portal pressure) (inferior vena-caval pressure)) to less than 12 $\mathrm{mm} \mathrm{Hg}$. Three patients subsequently had Angiomed stents (Angiomed, Karlsruhe, Germany) inserted to reduce the shunt size. In two patients in whom a thrombus was noted within the portal vein at the end of the procedure, a catheter was left within the shunt for regional infusion of low dose streptokinase for 24 hours. Prophylactic antibiotics (cefotaxime and amoxycillin) were given one hour before the procedure and continued for 48 hours thereafter and Doppler ultrasonography was performed prior to discharge to ensure shunt patency. Routine portography was undertaken at one to three months and six monthly thereafter to assess shunt function, or earlier in the event of rebleeding or reaccumulation of ascites. Early in our experience however, several shunts were left six to 12 months before initial angiographic assessment.

Encephalopathy was assessed clinically after six weeks then at three monthly intervals during outpatient review. Prophylactic lactulose and protein restriction were not routinely applied. Variceal rebleeding was defined as endoscopically confirmed variceal haemorrhage occurring more than 24 hours after TIPSS insertion. All shunt complications were confirmed angiographically with occlusion defined as absent flow through the shunt. Pseudo-intimal hyperplasia, hepatic vein stenosis, portal vein and shunt thrombosis were defined by the angiographic appearance in conjunction with either a $20 \%$ rise in portal pressure gradient or an increase in portal pressure gradient to $12 \mathrm{~mm} \mathrm{Hg}$ or more. Primary shunt patency was defined as the (preintervention) absence of any of the above shunt complications. Mean (SD) follow up (defined as time to death, most recent clinical review or liver transplantation) for all patients was $10 \cdot 7$ $(11.0)$ months and for survivors (patients alive up to October 1995) $18 \cdot 0$ (11.9) months.

\section{STATISTICAL ANALYSIS}

Results are expressed as mean (SD) or range where indicated. Paired Student's $t$ test was used to determine statistical significance and Kaplan-Meier method used for rates of variceal rebleeding, primary shunt patency, and survival.

\section{Results}

Tables II and III summarise the results.

\section{SHUNT PROCEDURE}

TIPSS placement was successful in 119 $(91.5 \%)$ patients. The procedure failed in 11 patients (10 of whom had variceal haemorrhage) because a main branch of the portal vein could not be punctured: four of these patients subsequently underwent shunt surgery and five 
TABLE II Results of TIPSS procedure and shunt complications

\begin{tabular}{lc}
\hline Successful TIPSS procedure (\%) & $119(91 \cdot 5)$ \\
PPG before TIPSS mean (SD) (mm Hg) & $17 \cdot 5(5 \cdot 9)$ \\
PPG after TIPSS (mm Hg) & $8 \cdot 6(3 \cdot 4)$ \\
Pre-intervention shunt patency (\%): & $47(71 \cdot 2)$ \\
6 months & $25(58 \cdot 1)$ \\
1 year & $3(21 \cdot 4)$ \\
2 years & 63 episodes in \\
Shunt complications: & $45(37 \cdot 8)$ patients: \\
& 29 \\
pseudo-intimal hyperplasia & 13 \\
hepatic vein stenosis & 5 \\
portal vein/shunt thrombosis & 16 \\
occlusion & \\
\hline
\end{tabular}

PPG=portal pressure gradient.

had further endoscopic therapy. Thirty day mortality in the failed TIPSS group with variceal haemorrhage was $70 \cdot 0 \%$.

Two procedure related deaths occurred from intraperitoneal haemorrhage because of an extrahepatic tear of the portal vein in one and puncture of the liver capsule in the other. One patient developed an epidural haemorrhage, which was diagnosed after the procedure but the exact relation to TIPSS placement was unclear. Other complications included portal vein thrombosis in two patients (successfully treated by local streptokinase infusion), portal vein dissection in one (successfully managed by stenting), and shunt dislocation or migration into the splenic vein in two. There were no clinically significant groin or neck haematomas. Mean (SD) portal pressure gradient

TABLE III Results of rebleeding, encephalopathy, ascites, and sepsis after TIPSS

\begin{tabular}{lc}
\hline Variceal rebleeding & 24 episodes in 16 patients $(13 \cdot 4 \%)$ \\
Non-variceal rebleeding & 9 patients $(7 \cdot 6 \%)$ \\
& 7 sclerotherapy ulcers \\
& 1 duodenal ulcer \\
& 1 Mallory-Weiss tear \\
Encephalopathy (\%) & $44(33 \cdot 8)$ \\
before TIPSS & $20(16 \cdot 8)$ \\
new/worse spontaneous encephalopathy & $9(7 \cdot 6)$ \\
new/worse encephalopathy, secondary to sepsis & $6(5 \cdot 0)$ \\
new/worse encephalopathy, secondary to bleeding & $86(66 \cdot 2)$ \\
Ascites (\%) & $56(65 \cdot 1)$ \\
before TIPSS & $14(25 \cdot 0)$ \\
improved after TIPSS & $17(13 \cdot 1)$ \\
reaccumulation & $14(11 \cdot 8)$ \\
primary indication for TIPSS & \\
Sepsis after TIPSS (\%) & \\
\hline
\end{tabular}

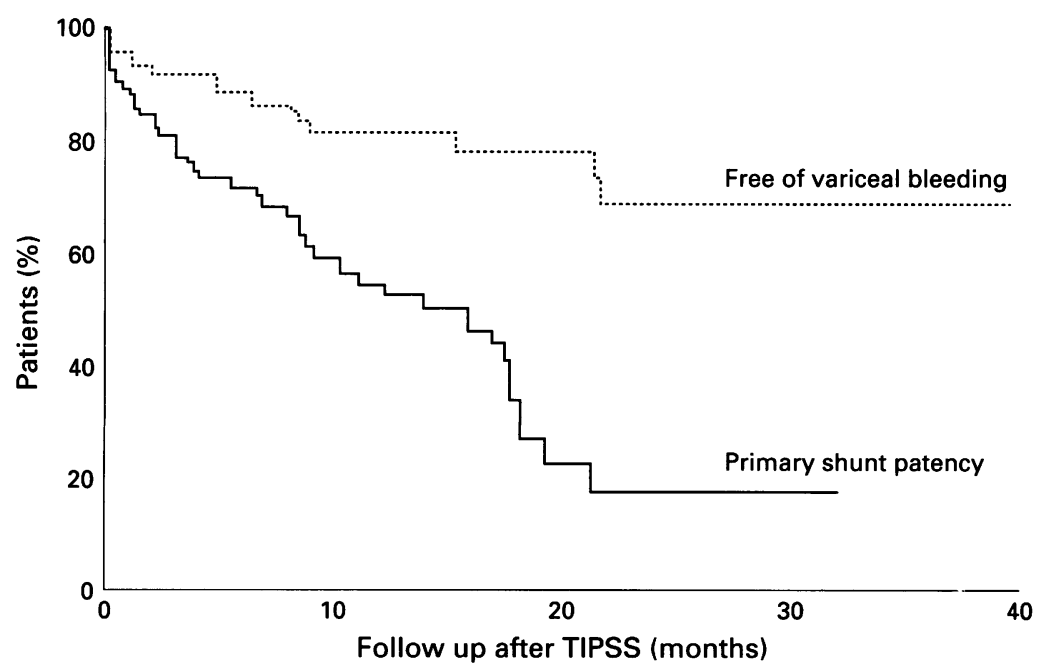

Figure 1: Kaplan-Meier analysis of patients free of variceal rebleeding and with primary shunt patency during follow up. was reduced from $17.5(5.9) \mathrm{mm} \mathrm{Hg}$ preTIPSS to $8.6(3.4) \mathrm{mm} \mathrm{Hg}(\mathrm{p}<0.001)$ after successful stent placement.

A total of 63 episodes of shunt complications were seen in 45 patients (see table II). Twenty nine of these were clinically significant (associated with variceal rebleeding or reaccumulation of ascites), with the others detected on routine surveillance. Fifty per cent of the shunt complications occurring less than one month after TIPSS were associated with variceal rebleeding, as were $41.7 \%$ of those occurring from one to three months, $35 \%$ from three to 12 months, and $23.5 \%$ from $12-24$ months. None of the shunt complications occurring more than two years after TIPSS were associated with variceal rebleeding. Taking follow up as most recent angiographic TIPSS assessment, pre-intervention shunt patency was $71 \cdot 2 \%$ at six months, $58 \cdot 1 \%$ at one year, and $21 \cdot 4 \%$ at two years (see Table II and Fig 1). No Palmaz stent had primary patency at two years. All shunt complications but one (in a patient who was transferred to an endoscopic banding programme and remains well) were successfully treated by balloon dilatation, local thrombolysis, shunt extension or parallel shunt placement (nine patients). The causes of shunt dysfunction are described in Table II.

\section{CLINICAL FOLLOW UP}

\section{Control of acute bleeding}

Thirty five patients had TIPSS for acute variceal haemorrhage uncontrolled despite sclerotherapy with or without tamponade. Eighteen of these patients were mechanically ventilated and 10 were haemodynamically unstable at time of TIPSS. The procedure was technically successful in 32 of these patients and the other three patients died: two from massive haemorrhage and one shortly after oesophageal transection. Fourteen of the remaining patients died during the index hospital admission: three each from acute on chronic liver failure, sepsis, and end stage liver failure, two from continued bleeding (one from a sclerotherapy ulcer confirmed at necropsy and one with disseminated intravascular coagulation and acidosis), two from cardiac arrests/myocardial infarct, and one from a procedure related intraperitoneal bleed. Two further patients had subsequent variceal rebleeds, both related to shunt insufficiency and successfully treated by angioplasty and shunt extension.

\section{Recurrent variceal bleeding}

TIPSS was successful in reducing recurrent variceal haemorrhage. There were 24 episodes of variceal re-bleeding in $16(13.4 \%)$ patients (see Fig 1), all of which were associated with shunt insufficiency and responded to dilatation or further stenting. Five patients underwent TIPSS for ectopic variceal haemorrhage (two rectal, two stomal, and one duodenal) and none of these patients have had a recurrent bleed. Non-variceal haemorrhage occurred in nine $(7 \cdot 6 \%)$ patients (see Table III). 


\section{Ascites}

Eighty six patients $(66 \cdot 2 \%)$ had ascites prior to TIPSS and this was the primary indication in 17 patients (seven of whom had established hepatorenal syndrome) (see Table III). The ascites improved (reduced or no diuretic requirement) in $56(65.1 \%)$ of the 86 patients, but reaccumulated in 14 . This was associated with shunt insufficiency in 11 patients and spontaneous bacterial peritonitis in two, but was responsive in all cases to shunt revision and antibiotics respectively. Of the 17 patients who had TIPSS performed for refractory ascites, improvement occurred in 11 and two have subsequently undergone successful liver transplantation. Those with biochemical evidence of renal dysfunction tended to respond less well after TIPSS insertion.

\section{Other indications}

TIPSS was performed for intractable bleeding from portal hypertensive gastropathy in six patients. Four of these have not required further transfusion and the other two have required one admission each for transfusion. Both of these patients had evidence of shunt dysfunction due to pseudo-intimal hyperplasia in association with a raised portal pressure gradient, which was successfully treated by angioplasty or shunt extension. TIPSS resulted in an improvement in platelet count from $13000 / 1$ to $50000 / 1$ in one patient with hypersplenism. Another patient had a large spontaneous shunt successfully embolised via the TIPSS for amelioration of intractable hepatic encephalopathy.

\section{Hepatic encephalopathy}

Forty four $(33.8 \%)$ patients were clinically encephalopathic prior to TIPSS and this resolved in $24(54.5 \%)$ after the procedure. Twenty $(16.8 \%)$ patients developed new or worsening spontaneous encephalopathy during follow up (15 within the first six months). A further $15(12.6 \%)$ patients developed encephalopathy secondary to sepsis or bleeding during follow up (see Table III). Reduction in shunt size was performed because of encephalopathy in four patients (successful in three), with all others responding to simple medical treatment.

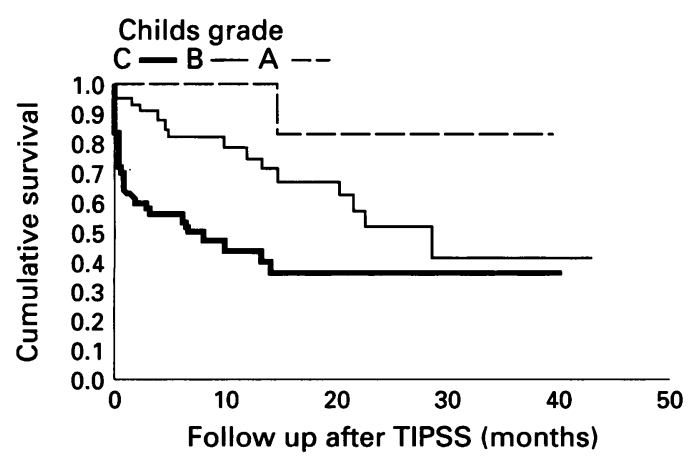

Figure 2: Kaplan-Meier analysis of patient survival after TIPSS by Childs grade. (Childs $A, n=12$; Childs $B, n=44$; Childs $C, n=61$. At 12 months, $n=9,23$, and 14 respectively.)
Sepsis

Fourteen $(11 \cdot 8 \%)$ patients developed clinically significant infections in the week after TIPSS (seven pulmonary, two spontaneous bacterial peritonitis, two related to central venous catheter, one cellulitis, and two of unknown origin). Sepsis was the cause of death in two patients during the index admission: one with pre-existing staphylococcal and fungal septicaemia and one with cystic fibrosis and preexisting lung sepsis. All other infective episodes responded to antibiotics.

\section{Liver function}

Approximately one third of patients exhibited a transient deterioration in their liver function tests in the first week after TIPSS, usually with doubling of bilirubin and alanine aminotransferase values. Three patients died with clinical features of acute liver failure, characterised by hypotension, renal failure, and hypoglycaemia. Two of these patients also had evidence of raised intracranial pressure on extradural pressure recordings or computed tomography. Childs-Pugh score did however improve at three to six months to $7 \cdot 6(2 \cdot 1)$ $(p=0.019)$ largely because of a reduction in ascites.

\section{Transplantation}

Thirteen patients have undergone orthotopic liver transplantation after TIPSS. Transplant was undertaken a mean of $7 \cdot 1(5.4)$ months after TIPSS and 11 of these patients remain alive and well.

\section{Mortality}

Of the 119 patients with successful TIPSS placement, 52 have died and 13 have undergone transplantation. Procedure related mortality was $1.5 \%$ and mean time to death was $6.0(8.9)$ months (range $0.03-45 \cdot 3)$. Mean follow up of survivors is $18.0(11.9)$ months (range $2 \cdot 0-43 \cdot 5)$. Thirty day mortality was $21 \cdot 8 \%$ (84.6\% of whom had Childs C disease) and six months survival $69 \cdot 2 \%$. One and two year survival is $62.3 \%$ and $46.5 \%$ respectively. Mortality was dependent on Childs grade at time of TIPSS (see Fig 2).

\section{Discussion}

This is only the second study with large numbers of patients and longterm follow up and our results are similar to the two year follow up of 90 patients reported by Laberge et $a l .{ }^{21}$ Shunt insertion was achieved with a reduction in the portal pressure gradient to below $12 \mathrm{~mm} \mathrm{Hg}$ in $91.5 \%$ patients. Our recurrent variceal rebleeding rate $(13.4 \%$ patients) and rate of new or worsening spontaneous encephalopathy ( $16.8 \%$ patients) compares favourably with most other series. ${ }^{12} 21-23$

TIPSS has established a position as a 'rescue procedure' for uncontrolled variceal bleeding. Of the 35 patients who had TIPSS for 
continued variceal haemorrhage despite sclerotherapy with or without balloon tamponade, shunt creation was successful in the vast majority $(91 \cdot 4 \%)$. Most $(77 \cdot 1 \%)$ of these patients had Childs $\mathrm{C}$ cirrhosis. Although only two patients had continued bleeding the inpatient mortality in this high risk group was $43 \cdot 7 \%$. The options of a surgical portosystemic shunt or transection in this situation have higher procedure related and early mortality. ${ }^{24}$ In addition transection has higher rebleeding rate $^{25}$ and surgical shunting has higher rates of encephalopathy ${ }^{26}$ while also compromising a subsequent liver transplant. It should be noted that in many cases TIPSS is performed in critically ill patients who would not be considered fit for surgery.

Similar to other investigators, ${ }^{21}$ we found shunt dysfunction in all patients with variceal rebleeding. There seems to be a steady attrition rate in shunt patency with time (Table II and Fig 1) with a primary (pre-intervention) patency of $21.4 \%$ at two years. We have previously shown that shunt dysfunction is more common with Palmaz stents than Wallstents, ${ }^{27}$ although it should be noted that our early (often Palmaz stented) patients were left longer than three months prior to initial angiographic assessment, therefore especially in this group it is difficult to be sure of the exact timing of shunt dysfunction. Accepting this limitation, if it is believed important to assess the TIPSS prior to a $20 \%$ risk of dysfunction, it is necessary to check the shunt at two months and then approximately six monthly thereafter. It would seem that early shunt dysfunction is more likely to be associated with variceal rebleeding than that occurring later after TIPSS, therefore even closer shunt assessment in the first few months after placement may be neccessary.

Although intervention maintained shunt patency in all but one patient when insufficiency was detected, most stents treated with balloon dilatation required repeat dilatation on follow up. This procedure would seem to have only a temporary effect and the longterm benefits of and exact indications for dilatation remain unclear. The current limitations of ultrasonographic methods of shunt assessment ${ }^{28}$ mean that direct portography remains the 'gold standard' for surveillance. This is an important limitation of TIPSS but hopefully the development of new covered stents will tackle this problem.

An ability to identify early shunt dysfunction and minimise encephalopathy together with a low incidence of rebleeding makes TIPSS an alternative to sclerotherapy in the treatment of recurrent variceal bleeding. Trials are currently underway to compare these two treatments in this situation. In the case of gastric variceal haemorrhage where current endoscopic treatments are unsatisfactory, we believe TIPSS to be the treatment of choice, as indicated by the comparatively large proportion of patients in our series with gastric varices.

Nine $(7 \cdot 6 \%)$ patients developed nonvariceal bleeding during follow up, mostly as a result of sclerotherapy ulcers and these were the cause of death in two patients. Sclero- therapy ulcers have been recognised as a major problem by many investigators and remain a major potential cause of morbidity and mortality no matter how effective the shunt is. The alternative of band ligation should reduce the frequency of this complication. ${ }^{29}$

New or worsening spontaneous encephalopathy was seen in $16.8 \%$ patients and a further $12.6 \%$ had new or worsening encephalopathy secondary to sepsis or bleeding after TIPSS. Considering however that $33.6 \%$ patients were encephalopathic prior to TIPSS, it is difficult to determine the exact role of the shunt in the development of encephalopathy in this group. In all but four patients (who went on to shunt reduction), the encephalopathy responded to simple medical treatment such as lactulose and protein restriction. This contrasts with the often debilitating encephalopathy seen in around one third of patients after non-selective surgical shunts ${ }^{11}$ and is probably because of the small stent diameter and intrahepatic position that encourages continued portal flow into the liver. ${ }^{30} \mathrm{~A}$ reduced incidence of encephalopathy has been reported in narrow portocaval H-grafts ${ }^{31}$ and selective splenorenal shunts ${ }^{32}$ however the associated risks of surgery and subsequent problems with transplantation must again be considered. Recent reports indicate that increasing age and a previous history of encephalopathy are the main predictors of encephalopathy after TIPSS ${ }^{33}$ and perhaps these patients should have narrower stents placed.

Treatment of patients with refractory ascites remains a major clinical problem. Apart from liver transplantation, the main therapeutic options are repeated large volume paracentesis and peritoneovenous shunting, both of which are associated with significant morbidity and prolonged inpatient management and may aggravate functional renal failure. Recent reports $^{1415}$ describe the benefits of TIPSS for refractory ascites although data are limited. The mechanism of action seems to be a combination of reduced portal pressure gradient and increased natriuresis, probably secondary to increased effective circulating plasma volume and neurohumeral factors. Survival is poor in patients with refractory ascites and any trial assessing TIPSS in this situation would need to assess quality of life and cost-benefit factors.

The place of TIPSS in the treatment of hepatorenal syndrome also remains controversial. Several authors have reported improvement in functional renal failure ${ }^{1534}$ and a preliminary study ${ }^{35}$ showed a decrease after TIPSS in the levels of endothelin 1, which is thought to have an important role in the syndrome. However as we found in this study, results are generally disappointing in this group of patients and they have a very poor prognosis without liver transplantation.

Similar to other investigators, ${ }^{36}$ we found a transient deterioration in liver function tests in a third of patients probably secondary to reduced hepatic perfusion. Three patients died soon after TIPSS with clinical features of acute liver failure, two of whom had evidence of raised intracranial pressure. This is unusual in patients with chronic liver disease but has been 
reported. ${ }^{37}$ All three of these patients were extremely ill at the time of TIPSS, however, with prolonged hypotension and requiring ventilation. The role of TIPSS in their clinical deterioration is therefore difficult to define, although any reduction in liver perfusion in such patients may be critical. Overall however there was a significant improvement in ChildsPugh score at three to six months largely due to improvement in ascites.

Procedure related mortality was $1.5 \%$, which is similar to most reported series and compares favourably with the operative mortality associated with surgical portosystemic shunts of around $10 \% .^{38}$ We found a relatively high 30 day mortality of $21 \cdot 8 \%$ compared with some groups, ${ }^{22}$ however mortality has been consistently shown to depend on Childs grade at time of TIPSS and our higher percentage of Childs $B$ and $C$ patients $(38.9 \%$ and $53.2 \%$ respectively) and higher numbers of emergency procedures $(26.9 \%)$ would account for this. Our one and two year survival of $62.3 \%$ and $46.5 \%$ respectively are similar to the recently reported series from San Francisco. ${ }^{21}$

Longterm survival after TIPSS will depend on the underlying severity of liver disease and improved survival due to reduced rebleeding will be difficult to detect. However the benefits of reduced morbidity, as a result of improved control of ascites and less variceal rebleeding should not be underestimated. We have previously shown that besides severity of liver disease, hyponatraemia and encephalopathy prior to TIPSS independently determine longterm survival. ${ }^{39}$ Thirteen of our patients subsequently underwent liver transplantation and the benefits of TIPSS as a 'bridge to transplantation' have been previously reported. ${ }^{40}$ In particular the ability to avoid surgery in the treatment of variceal bleeding before transplant is important.

In conclusion, TIPSS is a comparatively simple procedure that can be successfully performed even on critically ill patients. It is effective in the treatment of both acute and recurrent variceal haemorrhage (especially where they are not amenable to sclerotherapy), refractory ascites, and portal hypertensive gastropathy. Unlike surgical portosystemic shunts, it has the advantage of not compromising subsequent liver transplantation. Shunt dysfunction however is common and seems to increase linearly with time and variceal rebleeding and reaccumulation of ascites usually occur in the presence of shunt stenosis or occlusion. Regular surveillance by portography is therefore necessary and this represents an important limitation of TIPSS. Post-procedure encephalopathy is significant but generally easily treated and bleeding from sclerotherapy ulcers remains an important cause of morbidity and mortality. Trials are currently underway to compare TIPSS with sclerotherapy or banding in the treatment of first variceal haemorrhage and with paracentesis for refractory ascites, which will help define its exact role in these situations.

We thank Fiona Miller for technical assistance and data collection.
1 Richter GM, Noeldge G, Palmaz JC. The transjugular intrahepatic portosystemic stent-shunt (TIPSS): experience of results of a pilot study. Cardiovasc Intervent Radiol 1990; 13: 200-7.

2 Cales P, Pascal JP, Histoire naturelle des varices oesophagiennes au cours de la cirrhose (de la naissance a la rupture). Gastroenterol Clin Biol 1988; 12: 245-54.

3 Graham D, Smith J. The course of patients after variceal haemorrhage. Gastroenterology 1981; 80: 800-9.

4 Panes J, Teres J, Bosch J. Efficacy of balloon tamponade in treatment of bleeding gastric and oesophageal varices. Dig treatment of bleeding gast

5 Burroughs AK, McCormick PA, Hughes MD, Sprengers D, D'Heygere F, McIntyre R. Randomised double-blind controlled trial of somatostatin for variceal bleeding. Emergency control and prevention of early variceal rebleeding. Gastroenterology 1990; 99: 1388-95.

6 Westaby D, Hayes PC, Gimson AES, Polson RJ, Williams R. Controlled trial of ejection sclerotherapy for active variceal bleeding. Hepatology 1989; 9: 274-7.

7 Stiegman GV, Goff JS, Michaletz-Onody PA, Korula J, Lieberman D, Saeed ZA, et al. Endoscopic sclerotherapy as compared with band ligation for bleeding oesophageal varices. $N$ Engl $₹$ Med 1992; 326: 1527-32.

8 Burroughs AK, Hamilton G, Philips A, Mezzanotte G, McIntyre N, Hobbs KEF. A comparison of sclerotherapy with staple transection of the oesophagus for the with staple transection of the oesophagus for the emergency control of bleeding from

9 Editorial. Emergency portocaval shunts. (Anonymous). Lancet 1991; 337: 952.

10 Cello J, Grendall J, Crass R, Weber T, Trunkey D. Endoscopic sclerotherapy versus portocaval shunt in patients with severe cirrhosis and acute variceal haemorrhage: long term follow up. $N$ Engl $\mathcal{F}$ Med 1987; 316: 11-5.

11 Franco D, Smadja C. Prevention of recurrent variceal bleeding: surgical procedures. In: Benhamou JP, Lebrec D, eds. Clinics in gastroenterology: portal hypertension. London: WB Saunders, 1985: 233-57.

12 LaBerge JM, Ring EJ, Gordon RL, Lake JR, Docherty MM, Somberg KA, et al. Creation of transjugular intrahepatic portosystemic shunts with Wallstent endoprosthesis: results in 100 patients. Radiology 1993; 187: 413-20

13 Moore K, Wilkinson S, Williams R. Ascites and renal dysfunction in liver disease. In: Millward-Sadler GH, Wright R, Arthur NJP, eds. Wright's liver and biliary disease. London: Saunders, 1992: 1346-71.

14 Quiroga J, Sangro B, Nunez M, et al. Transjugular intrahepatic portal-systemic shunt in the treatment of refractory ascites: Effect on clinical, renal, humeral and haemodynamic parameters. Hepatology 1995; 21: 986-94.

15 Ochs A, Rossle $\mathrm{M}$, Haag MD, et al. The transjugular intrahepatic portosystemic stent-shunt procedure for intrahepatic portosystemic stent-shunt procedure

16 Jalan R, Redhead DN, Simpson KJ, Elton RA, Hayes PC. Transjugular intrahepatic portosystemic stent-shunt (TIPSS): long-term follow up. $Q \mathcal{F}$ Med 1994; 87: 565-73.

17 PeltzerNY, Ring EJ, LaBerge JM, Haskal ZJ, Radosevich PM, Gordon RL. Treatment of Budd-Chiari syndrome with transjugular intrahepatic portosystemic shunt. $\mathcal{f}$ Vasc Intervent Radiol 1993; 4: 263-7.

18 Strauss RM, Martin LG, Kaufman SL, Boyer TD. Transjugular intrahepatic portal systemic shunt for the management of symptomatic cirrhotic hydrothorax. $A m ~ f$ Gastroenterol 1994; 89: 1520-2.

19 Richter GM, Noeledge G, Palmaz JC. The transjugular intrahepatic portosystemic stent-shunt (TIPSS): experiintrahepatic portosystemic stent-shunt (TIPSS): experiRadiol 1990; 13: $200-7$.

20 Chalmers N, Redhead DN, Simpson KJ, Hayes PC. Transjugular intrahepatic portosystemic stent shunt (TIPSS) Early clinical experience. Clin Radiol 1992; 46: 166-9.

21 LaBerge JM, Somberg KA, Lake JR, et al. Two-year outcome following transjugular intrahepatic portosystemic shunt for variceal bleeding: results in 90 patients. Gastroenterology 1995; 108: 1143-51.

22 Rossle M, Haag K, Ochs A, et al. The transjugular intrahepatic portosystemic stent-shunt procedure for variceal bleeding. $N$ Engl f Med 1994; 330: 165-71.

23 Coldwell DM, Ring EJ, Rees CR, et al. Multicenter Investigation of the role of transjugular intrahepatic portosystemic shunt in management of portal hyperportosystemic shunt in management of por

24 Franco D, Smadja C. Prevention of recurrent variceal bleeding: Surgical procedures. Clin Gastroenterol 1985; 12: 233-57.

25 Matory WE Jr, Sedgwick CE, Rossi RL. Non-shunting procedures in management of bleeding oesophagea varices. Surg Clin North Am 1980; 60: 281-95.

26 Grace ND. The side-to-side shunt revisisted. N Engl f Med 1994; 330: 208-9.

27 Jalan R, Redhead DN, Ferguson J, Simpson KJ, Elton RA, Hayes PC. Wallstents or Palmaz stents for the transjugular
intrahepatic portosystemic stent-shunt (TIPSS). $\mathcal{f}$ Intervent Radiol 1994; 9: 147-52.

28 Jalan R, Ferguson J, Allan PL, Redhead DN, Hayes PC. The role of duplex and colour flow doppler utrasonography in the assessment of TIPSS shunt function. Gut raphy in the assessment 36 (suppl 1): A20.

29 Hou MC, Lin HC, Kuo BI, Chen CH, Lee FY, Lee SD. Comparison of endoscopic variceal injection sclerotherapy and ligation for the treatment of esophageal 
variceal hemorrhage: a prospective randomized trial. Hepatology 1995; 21: 1517-22.

30 Lacy AM, Nevasa M, Gilabert R, et al. Long-term affects of distal splenorenal shunt on hepatic haemodynamic and liver function in patients with cirrhosis: importance of reversal of portal blood flow. Hepatology 1992; 15: 616-22.

31 Johansen K. Prospective comparison of portal versus total portal decompression for bleeding oesophageal varices. Surg Gynaecol obstet 1992; 175: 528-34.

32 Langer B, Taylor BR, Mackenzie DR, et al. Further repor of a prospective randomised trial comparing distal splenorenal shunt with end-to-side portacaval shunt. splenorenal shunt with end-to-sic

33 Sanyal AJ, Freedman AM, Shiffman ML, Purdum PP, Leketic VA, Cheatham AK. Portosystemic encephalopathy after transjugular intrahepatic portosystemic shun results of a prospective controlled study. Hepatology 1994; 20: 46-55.

34 Lake JR, Ring EJ, LaBerge J, Gordon R, Roberts J, Ascher N. Transjugular intrahepatic portocaval stent shunts in patients with renal insufficiency. Transplant Proc 1993; 25: 1766-7.
35 Martinet JP, Legault L, Cernacek P, et al. Effect of TIPSS on splanchnic and renal production of endothelins. Hepatology 1994; 20: 113A.

36 Rossle M, Sellinger M, Ochs A, Haag K. Liver function and blood flow before and after TIPSS. Hepatology 1993; 18: 285A.

37 Crippin JS, Gross JB, Lindor KD. Increased intracranial pressure and hepatic encephalopathy in chronic liver disease. Am $\mathcal{f}$ Gastroenterol 1992; 87: 879-82.

38 Henderson JM, Millikan WJ, Warren WD. The distal splenorenal shunt: an update. World $f$ Surg 1984; 8: s22-32.

39 Jalan R, Elton R, Redhead DN, Finlayson NDC, Hayes PC. Analysis of prognostic variables in the prediction of Analysis of prognostic variables in the prediction of
mortality, shunt failure, variceal rebleeding and encephalopathy following the transjugular intrahepatic portosystemic stent-shunt for variceal haemorrhage. $\mathcal{J}$ Hepatol 1995; 23: 123-8.

40 John TG, Jalan R, Redhead DN, Hayes PC, Sanfey HA Garden OJ. Transjugular intrahepatic portosystemic stent-shunt (TIPSS) insertion as a preclude to orthotopic liver transplantation (OLT) in patients with severe portal hypertension. Gut 1994; 35 (suppl 5): S24. 